\title{
MINISTROS Y GOBIERNO EN EL ESTADO MODERNO. UN ANALISIS REALISTA
}

\author{
Por JOAQUIN TOMAS VILLARROYA
}

\begin{abstract}
Sumario: INTRoducción.-EL NúMERo de MINISTERIos.-La TAREa de IOS Ministros.-Los MiNistros técnicos.-La tarea del pResidente dEL Gobierno.--El MiNistro de Asuntos Exteriores. El ministro de Hacienda.-Los Consejos de Ministros.-La estabilidad del Gobierno.-Conclusión.
\end{abstract}

\section{Introducción}

El presente estudio se propone analizar - dentro de las naturales limitaciones- determinados aspectos de la condición y tarea de los ministros y del funcionamiento del Gobierno en el Estado moderno. Los materiales que se utilizan no son los textos constitucionales o legales; o, al menos, a éstos se les concede sólo la atención que se ha considerado imprescindible. Las fuentes de este estudio se encuentran en los libros y escritos de los tratadistas que analizan no sólo los mecanismos constitucionales, sino también su aplicación práctica; $y$, sobre todo, en las $\mathrm{Me}$ morias que nos han dejado gobernantes y políticos: ellos nos ilustran sobre las coincidencias y contrastes que existen entre la norma y la realidad; nos ofrecen datos sobre el funciona- 
DA-1980, núm. 188. JOAQUÍN TOMÁS VILLARROYA. Ministros y Gobierno en el Estado moderno. Un...

miento de los mecanismos gubernamentales; nos permiten llegar a un conocimiento aproximado de la realidad política. Por esta razón, en las páginas que siguen se deja amplio espacio a los recuerdos y exposiciones directas de aquellos políticos y gobernantes; frecuentemente, este estudio se limita-y pretende limitarse- a una selección y sistematización de los materiales contenidos en aquellas Memorias (1).

\section{El número de Ministerios}

La fijación del número de Ministerios es tema delicado y controvertido. De una parte, se pretende que debe realizarse por medio de una ley por motivos varios: la importancia de la materia; la necesidad de dar consistencia y seguridad a la misma; la conveniencia de sustraerla a exigencias partidistas o ambiciones personales. De otra parte, se alega que el Gobierno o su presidente deben fijar aquel número por razones también varias: la salvaguarda del principio de la división de poderes; la consideración de que aquéllos están más y mejor capacitados para determinar su propia composición y organización; la necesidad de atender exigencias objetivas y reales sin esperar las dilaciones que lleva consigo la elaboración y aprobación de una ley. En términos generales, puede decirse que la fijación por medio de ley es una aspiración frecuentemente expresada, pero que no ha conseguido imponerse en la práctica. Quizá en este punto sea interesante recordar experiencias e intentos.

En Francia, durante la Tercera República, se aprobó la Ley de Finanzas de 20 de junio de 1920 , que, en su artículo 8. , decia: "La creación de Ministerios y de Subsecretarios de Estado, las transferencias de competencias de un Departamento ministerial a otro, sólo pueden llevarse a cabo mediante ley que haya entrado en vigor después del voto de esta ley." Duguit ponderó la medida contenida en este precepto esperando que suprimiría creaciones y transformaciones continuas y abusivas de Ministe-

(1) Para evitar la dispersión, el estudio se concentra en el examen de la vida ministerial y política en Francia, Italia, Inglaterra y la República Federal Alemana. En cambio, se prescinde de España por cuanto requeriria un análisis especial y por ocuparse del tema otros estudios recogidos en este volumen. 
DA-1980, núm. 188. JOAQUÍN TOMÁS VILLARROYA. Ministros y Gobierno en el Estado moderno. Un...

rios. En cambio, Barthelemy, ya con una cierta perspectiva, señalaba los inconvenientes y dificultades que su aplicación suponía: “Un Presidente del Consejo -escribia- en el momento de formar su Ministerio, debía limitarse a cubrir los puestos existentes, en el Ministerio precedente. Después, debía acudir a la Cámara, depositar un proyecto de ley para la creación de nuevos Ministerios o Subsecretarías. El proyecto pasaría a las Comisiones competentes; se formularia el informe correspondiente; la Cámara discutiría, votaria; después se seguiría el mismo procedimiento en el Senado. El Presidente de la República promulgaría la ley, la publicaria y solamente entonces se podrían cubrir los puestos nuevamente creados... Es suficiente esta explicación para que se advierta inmediatamente su falta de viabilidad. La experiencia demuestra que es difícil formar un Ministerio. Si se aplicase la ley, la tarea resultaría imposible. De esta manera, la ley nunca se ha aplicado. Cada uno continúa, como antes, formando su Ministerio según le parece, y se limita a solicitar a las Cámaras los créditos necesarios colocando así al Parlamento frente al hecho consumado. El voto de los créditos se considera como aprobación definitiva...» (2).

Los intentos de regular con una cierta fijeza la creación, modificación o supresión de Ministerios, no han conseguido hasta el momento resultados prácticos. En Italia, el artículo 95, 3, de la Constitución dice: «La Ley proveerá al ordenamiento de la Presidencia del Gobierno y determinará el número, las atribuciones y la organización de los Ministerios.» En la línea de este pensamiento, el artículo 18, párrafo último, del proyecto de ley presentadó por el Gobierno Segni en 1956, disponia que la creación, supresión o modificación de los Ministerios se realizaría por medio de una ley; es decir: siguiendo la pauta fijada por la Constitución se establecía una reserva de ley en relación a la fijación o alteración del número de Ministerios. Esta reserva legal se justificaba por la naturaleza de la materia, exquisitamente política, que debía confiarse a la decisión soberana del Parlamento; de otra parte, el rigor del artículo 18 del proyecto quedaba parcialmente atenuado por cuanto el artículo $5 .^{\circ}$, apartado 2 , dispo-

(2) Bantheldamy y Dugz: Traité du Droit Constitutionnel, Paris, 1933, p. 643. 
DA-1980, núm. 188. JOAQUÍN TOMÁS VILLARROYA. Ministros y Gobierno en el Estado moderno. Un...

Estudios

108

nía que el presidente de la República, a propuesta del presidente del Gobierno, podía nombrar ministros sin cartera en número no superior a cinco (3). En Alemania, el Reglamento interior del Gobierno federal de 11 de mayo de 1951, pese a su detallismo y minuciosidad, no determina el número de Ministerios que deben componerlo. El primer Gobierno Adenauer, formado en 20 de septiembre de 1949, contaba, aparte del canciller, con trece $\mathrm{Mi}$ nisterios, entre los cuales el de Asuntos Panalemanes, el de Refugiados y el de Reconstrucción guardaban relación directa con los temas y problemas del momento; el segundo Gobierno Adenauer, formado el día 20 de octubre de 1953, contaba con $18 \mathrm{Mi}$ nisterios, entre los cuales cuatro debian ocuparse de tareas concretas y determinadas; el tercer Gobierno Adenauer, formado en 29 de octubre de 1957, contaba con 17 ministros, entre los cuales uno debía ocuparse de la Familia y de la Juventud, otro de la Energía Atómica y un tercero de las Propiedades Económicas de la Federación (4). En la Francia de la V República, bajo las presidencias del general De Gaulle y de Pompidou, el número de ministros ordinarios ha oscilado entre 14 y 16; el de ministros delegados, entre uno y tres; el de secretarios de Estado, entre cuatro y 20. Debré en 1962, en Au service de la Nation, pedia una refundición de Ministerios y la creación de un vasto Ministerio de Cooperación; Pompidou en su época de primer ministro $\mathrm{y}$, posteriormente, Chaban-Delmas han postulado una racionalización de la organización ministerial: hasta ahora, los resultados han sido muy limitados, insuficientes y criticables (5).

En rigor, la creación de nuevos Ministerios para dar satisfacción a apetencias personales o partidistas perturba el buen funcionamiento del Gobierno, supone un atentado a la ética política y escandaliza, justamente, a la opinión pública. Sin embargo, parece lógico que, en nuestros días, se reconozca a quien debe formar Ministerio una cierta discrecionalidad en la ordenación de su estructura que permita atender debidamente las necesidades nuevas que continuamente surgen; mejorar el funcionamiento

(3) El texto del proyecto en Giurisprudenza Costituzionale, 1956.

(4) Los datos en AmpHoux: Le Chancellier Fédéral dans le régime constitutionnel de la République Fédéral d'Alemagne, París, 1962, pp. 545 y ss.

(5) Los datos en Claisse: Le premier Ministre de la Ve République, París, 1972, p. 86. 
DA-1980, núm. 188. JOAQUÍN TOMÁS VILLARROYA. Ministros y Gobiẹno en el Estado moderno. Un...

de los servicios públicos y remediar exigencias coyunturales. De otra parte, la puesta en práctica de tales innovaciones aconsejará su conservación, alteración o supresión. La organización y funcionamiento del Gobierno no puede quedar estabilizada en un mundo cambiante; pero tales modificaciones han de introducirse con arreglo a criterios de ética y eficacia. Cuando así sucede, la modificación de la estructura ministerial no sólo está justificada, sino que es obligada. La conciencia de la clase política y la educación cívica en cada país pueden jugar un papel decisivo.

En este punto, la referencia inglesa resulta, una vez más, ejemplar. Wilson, en 1964, introdujo modificaciones considerables en la composición del Ministerio que, por ser razonables, fueron aceptadas sin reservas serias; y él mismo las ha descrito y justificado con detalle en su libro sobre su propia experiencia gubernamental. Wilson señala que al tiempo de ocupar el poder en 1964 estaba decidido a introducir innovaciones en la maquinaria del Gobierno, con nuevos Ministerios que respondiesen a los problemas prioritarios de Gran Bretaña. En primer lugar, sin perjuicio de las competencias del canciller del Exchequer, consideró que "Gran Bretaña sólo podía confiar en alcanzar su seguridad económica mediante la reconstrucción y modernización fundamental de la industria, bajo la dirección de un departamento por lo menos tan poderoso como el del Tesoro. Este nuevo departamento se ocuparía de los recursos reales, de la planificación económica, de reforzar nuestra capacidad para exportar y ahorrar importaciones, de incrementar la productividad y hacernos más competitivos en los mercados interno y de exportación...» (6). En segundo lugar, Wilson decidió la creación de un Ministerio de Tecnologia que cumpliese dos tareas que los departamentos hasta entonces existentes realizaban de manera insuficiente e inadecuada: de una parte, procurar sun incremento de la productividad y de la eficiencia, particularmente dentro de las industrias que necesitaban urgentemente una reestructuración y modernización..."; de otra parte, «acelerar la aplicación de nuevos métodos científicos a la producción industrial», por cuanto

(6) Wilson: El Gobierno laborista. Trad. esp., 1974, p. 24. 
DA-1980, núm. 188. JOAQUÍN TOMÁS VILLARROYA. Ministros y Gobierno en el Estado moderno. Un...

la Gran Bretaña «había hecho siempre un buen papel en el laboratorio cientifico, pero demasiado a menudo los resultados de las investigaciones fundamentales realizadas aquí habian sido revestidos con la necesaria experimentación en industrias extranjeras..." (7). En tercer lugar, creó un Ministerio de Territorio y Planificación que aliviase al Departamento de Vivienda y Gobierno Local; pero que quedó prontamente disminuido-dato interesante a retener-por las resistencias encontradas en el disciplinado servicio civil inglés: "A los pocos días de su concepción -escribe-el Ministerio de Vivienda y Gobierno Local había ganado la batalla..." (8). Por último, en cuarto lugar, Wilson consideró oportuno la creación del Departamento de Gales dentro de la Secretaria de Estado para Gales con un puesto en el Gabinete: "Se inspiraba - concluye-en gran medida en la Oficina de Escocia, existente desde 1885, y tenía plena responsabilidad para el Gobierno local, vivienda y planificación, planificación económica, bosques y acondicionamientos de terrenos abandonados y posteriormente para el turismo y sanidad, siendo también corresponsable en materias agrícolas junto con el correspondiente Ministerio..." (9). En conclusión, estos cambios se inspiraban en necesidades objetivas justificables $\mathrm{y}$ justificadas; los resortes éticos de la vida política inglesa actuaron una vez más; por esta razón, tales cambios resultaron generalmente eficaces y en todo caso fueron aceptados sin reservas serias.

\section{La tarea de los ministros}

Las Constituciones dedican, generalmente, una atención muy escasa a la condición y competencia de los ministros. En la Constitución italiana, el artículo 92 señala que el presidente de la República nombrará al presidente del Consejo y, a propuesta de éste, a los ministros; el 95 dispone que los ministros serán responsables colectivamente de los actos del Consejo de Ministros e individualmente de los de sus propios departamentos; el mismo artículo 95 precisa que la Ley regulará el número, competencia

(7) Ibid., p. 30.

(8) Ibid., p. 31.

(9) Ibid., p. 32 . 
DA-1980, núm. 188. JOAQUÍN TOMÁS VILLARROYA. Ministros y Gobierno en el Estado moderno. Un...

y organización de los Ministerios, y el 96 advierte que el presidente del Consejo y los ministros podrán ser acusados por el Parlamento, en sesión conjunta, por delitos cometidos en el ejercicio de sus funciones. La Ley Fundamental de Bonn, de 1949, en su artículo 64, señala que los ministros federales serán nombrados y relevados por el presidente federal a propuesta del canciller federal; en su artículo 65 precisa que, dentro de la línea política fijada por el canciller federal, cada ministro dirige por sí y bajo su propia responsabilidad los asuntos de su cartera; en el 66 establece un sumario estatuto de incompatibilidades, y en el 65 se ha querido precisar que el ministro federal de Defensa ejerce la jefatura y el mando de las Fuerzas Armadas. La Constitución francesa de 1958 dispone, en su artículo 8, que el presidente de la República, a proposición del primer ministro, nombra a los otros miembros del Gobierno y pone fin a sus funciones; en el artículo 21, que el primer ministro puede delegar algunos de sus poderes en los ministros; en el 22, que los actos del primer ministro deben ser refrendados, en su caso, por los ministros encargados de su ejecución, y en el 23 , establece una relación de incompatibilidades de las cuales la más notoria y característica es la que se refiere al ejercicio de todo mandato parlamentario. De esta manera, puede concluirse, en términos aproximativos, que las Constituciones señalan el modo de proceder al nombramiento y separación de los ministros, determinados extremos de su estatuto jurídico, la responsabilidad en el ejercicio de sus funciones y otros temas aislados e importantes; pero no acostumbran a fijar sus competencias y no revelan la tarea dificil, plural y abrumadora que recae sobre los ministros.

En cambio, normas de distinto rango proponen o han tratado de proponer una relación de las atribuciones que corresponden a los ministros. En la República Federal Alemana, el Reglamento Interior del Gobierno Federal cuida de detallar las funciones de los ministros; pero, además, regula de manera minuciosa y aun curiosa el comportamiento de los mismos: el artículo 12 dispone que el ministro que abandone la sede del Gobierno federal por una duración superior a un dia debe previamente ponerlo en conocimiento del canciller; si se ausenta por más de tres días o debe desplazarse al extranjero, solicitará el permiso de éste; si 
DA-1980, núm. 188. JOAQUÍN TOMÁS VILLARROYA. Ministros y Gobierno en el Estado moderno. Un...

quiere aceptar una invitación para viajar a otro país, necesitará autorización del canciller, y, en todo caso de ausencia, deberá informar al canciller de la dirección en que puede ser localizado En Italia, en 1956, siendo Segni presidente del Consejo de Ministros, se presentó en el Senado un interesante proyecto de ley ya citado - que no llegó a término-, en que recogiendo estudios y experiencias se regulaba con detalle el número y denominación de los Ministerios, las competencias y funcionamiento del Consejo de Ministros, el estatuto y atribuciones de los ministros y otros extremos de valor y alcance diferentes, pero que permiten una aproximación al conocimiento y ponderación de las tareas y cargas que pesan sobre un ministro.

En efecto, las tareas de un ministro son muchas en número, plurales en su contenido y variedad, abrumadoras en su peso. Laski, ya en 1931, escribia: "Consideremos las tareas que caen sobre un ministro importante en el Estado moderno: tiene que resolver los asuntos de su departamento, tiene que imponerse, por lo menos en líneas generales, de los principales problemas planteados al Gabinete; ha de dedicar la atención necesaria a la Asamblea legislativa, asistir a ella con frecuencia para tomar parte en las votaciones esenciales. Hoy, que los asuntos exteriores han dejado de ser competencia de un solo ministro, ha de contar con que tiene que participar en las conferencias internacionales, tiene que hacer discursos políticos, pero sin perder de vista que, dada la posición que ocupa, cada palabra que pronuncie será escrupulosamente analizada; las funciones protocolarias también ocupan horas de su precioso tiempo. $Y$ en los ratos de tiempo que le quedan ha de encontrar tiempo no sólo para satisfacer siquiera alguna de las demandas del afecto doméstico, sino también para meditar —en el aislamiento en el que nacen todas las ideas de altura-sobre los acontecimientos y sobre la política cuyos destinos está llamado a modelar...” (10). Junto a este testimonio, puede situarse el de Giraud, que, en 1938, preocupado también por la crisis de la democracia, abordaba el mismo tema: «El riesgo de que los gobernantes -escribíasean aplastados por el peso de su cargo es grande. Los ministros,

(10) LaskI: La democracia en crisis. Trad. esp., 1934, p. 82. 
DA-1980, núm. 188. JOAQUÍN TOMÁS VILLARROYA. Ministros y Gobierno en el Estado moderno. Un...

que no tienen un instante de respiro, aun cuando estén dotados. de una salud de hierro y de una gran capacidad de trabajo, conocen, después de algún tiempo, el ahogo y la fatiga. Es lamentable para ellos y para su función, que se realizará con menos energía. La absorción continua por una tarea demasiado amplia supone, en efecto, grandes inconvenientes. Los gobernantes no aplican una técnica rutinaria, no avanzan en un camino en que todo está hecho; al contrario, deben resolver problemas complejos cambiantes $y$, por consiguiente, necesitan de una mente despejada, de un juicio sereno y de tiempo para reflexionar. Es necesario que antes de adoptar determinadas decisiones puedan contemplar las cosas con una cierta perspectiva, valorar las opiniones que ha escuchado, discernir lo esencial de lo accesorio y de lo efímero. Para ello, sería necesario recogimiento. Los ministros más importantes se lamentan de no tenerlo..." (11). Todas estas observaciones conservan su actualidad; más todavia: desde los tiempos en que escribían Laski y Giraud, las tareas, obligaciones y funciones de los ministros han aumentado sensiblemente.

Este ministro, desbordado por el trabajo, solicitado por audiencias y compromisos, anegado por informes y datos, olvidado o contrariado por sus colegas, no puede cumplir las tareas de su cargo con el conocimiento, prudencia y energía que requiere el buen gobierno de los asuntos públicos. Esta impotencia produce consecuencias varias:

a) El ministro, en la adopción de decisiones, graves o secundarias, se ve desplazado por los funcionarios que están a sus órdenes. Sobre este punto, volveremos más adelante; pero conviene señalar que ya Laski advirtió que el ministro, por razón de su inexperiencia o de sus ocupaciones, se encontraba en manos de funcionarios que han alcanzado una posición de autoridad muy superior a la de cualquier época anterior: "El ministro-escribia-no puede arriesgarse a hacer desatinos; sus funcionarios constituyen el máximo de salvaguardia contra ellos. Si quiere lograr que el período de su gestión sea un éxito, habrá de aceptar una gran parte de las ideas producto de la autorizada experiencia

(11) Giraud: La crise de la demacratie et le renforcement du pouvoir executif, $\mathrm{Pa}-$ ris, 1938, p. 170. 
DA-1980, núm. 188. JOAQUÍN TOMÁS VILLARROYA. Ministros y Gobierno en el Estado moderno. Un...

de sus funcionarios. Cualquiera que medite en los trabajos que requiere la aplicación de un gran experimento social como, por ejemplo, el seguro contra el paro o la realización de una gran política de carreteras, comprenderá fácilmente por qué ha cambiado dignidades contra poder...» (12).

b) El ministro firma sin tener conocimiento suficiente de lo que decreta o autoriza; frecuentemente, sin tener noticia superficial de ello. En nuestros días, Peyreffitte nos ha dejado su propio testimonio: "Cuando llegué a la calle Granelle -anota-, los ujieres me trajeron varias cestas de mimbres en las que se apilaban centenares de nombramientos y traslados que componen el movimiento. Directores de instituto y principalmente de colegio esperaban de mi rúbrica su nuevo destino. Como consecuencia, cada tarde, traían a mi despacho la carretilla de la firma. ¿Qué sentido podía revestir este gesto? ¿Qué medios tenía yo de comprobar si aquel profesor del que lo ignoraba todo sería un buen director del colegio en Neurthe-et-Moselle? La responsabilidad incumbía a un ciego, y los verdaderos responsables de la decisión se escamoteaban dentro de los repliegues del sistema..." (13).

c) El ministro, impotente para conocer los asuntos de su propio departamento, se desentiende de todos los de los demás y de las tareas generales del Gobierno con todos los inconvenientes que ello supone en un cometido que requiere unidad de pensamiento y conjugación de esfuerzos. En este sentido, Leon Blum formuló una denuncia que conserva, seguramente, todavía validez: "Cada una de nuestras Administraciones es un organismo cerrado que pretende bastarse a sí mismo; cada ministro tiene ante sí una perspectiva tan amplia de preocupaciones $\mathrm{y}$ trabajos que no puede traspasar su propio horizonte. $\mathrm{Y}, \sin \mathrm{em}$ bargo, no existe ninguna clase de asuntos que puedan arreglarse independientemente de los demás; no existe ninguno cuyo arreglo deje de afectar a la prosperidad general del país... Los ministros están separados y actúan como si cada uno de ellos estuviese solo; los negocios son comunes y solidarios. De cualquier manera que se quiera presentarlos, atribuirlos o distribuirlos, son nego-

(12) LASKT, op. cit., p. 89.

(13) Peyreprite: El mal latino. Trad. esp., 1978, pp. 315-16. 
DA-1980, núm. 188. JOAQUÍN TOMÁS VILLARROYA. Ministros y Gobierno en el Estado moderno. Un...

cios del país, y forman un todo, como los asuntos de una fábrica o de un negocio, y solamente se puede apreciar la importancia de cada uno cuando se les pone en relación con el conjunto total. Un ministro particular, prisionero en el estudio egoísta de los asuntos que le están encomendados, no se halla en condiciones de subordinar o coordinar la solución con los otros intereses particulares que él ignora, $\mathrm{y}$, sobre todo, con los intereses generales cuyos otros elementos se le escapan..." (14).

\section{Los ministros técnicos}

Un ministro que accede por vez primera al cargo puede encontrarse totalmente desorientado. Este ministro llega a una casa extraña, no conoce su distribución, no conoce las gentes que la habitan, no conoce los problemas que le afectan. De ahí la tentación de recurrir a ministros que sean técnicos en las materias del departamento que se les va a confiar; de seleccionar los ministros entre aquellos que poseen una competencia especial. Esta tendencia encuentra apoyo en la opinión pública: la opinión se siente mal impresionada cuando presencia la llegada a un departamento de un político o de un parlamentario que, por razón de su pasado, no se encuentra debidamente preparado. La opinión se escandaliza todavia más por lo que Barthelemy llamaba el vals de la carteras: un parlamentario que pasa de Instrucción Pública a Marina, de Comercio a Guerra. Y, sin embargo, conviene tener presente que un político, sin preparación previa o con una formación diversa de la que requeriría el puesto a que es llamado, puede, por sus condiciones personales, por su capacidad de asimilación, por la experiencia, llegar a ser un buen ministro y aun un ministro excepcional: tal fue el caso, en la IV República francesa de Robert Schumann. En cambio, un técnico, por grande que sea su preparación en las materias del ramo que es llamado a dirigir, no ha de ser necesariamente un ministro eficaz.

(14) Buum: La reforme gouvernamentale, Paris, 1938. Recogido de L'Oeuvre de Leon Blum, Paris, 1872, t. III, p. 516. 
DA-1980, núm. 188. JOAQUÍN TOMÁS VILLARROYA. Ministros y Gobierno en el Estado moderno. Un...

En este sentido, es interesante recoger dos opiniones doctrinales. La primera, propuesta por Barthelemy, en 1933, decía así: «En todos los órdenes de la actividad humana, la inteligencia general debe colaborar con la competencia técnica y controlarla: esta regla se aplica de manera particular al Gobierno. Un propietario dotado de buen sentido no se confía a un arquitecto encontrado al azar; escoge un arquitecto y a través de esta selección, él, supuestamente incompetente, ejerce un primer control sobre el técnico; después le señala los criterios que el arquitecto realizará por medios adecuados: la casa tendrá tales caracteres, tal destino, tal distribución general; la construcción no deberá rebasar ciertos costes; el propietario controlará los planes que le serán sometidos para asegurarse que son conformes a su voluntad; vigilará incluso la ejecución y exigirá que le rinda cuentas..." (15). Una segunda observación ha sido propuesta, en nuestros días, por Goguel y Grosser: «La competencia escriben-incluye el sentido político y la autoridad sobre la Administración: en este sentido, el hombre político no es a priori más incompetente que un alto funcionario llamado a la responsabilidad ministerial. De otra parte, el técnico, ¿es realmente competente si no dirige el ministeria que corresponde a su especialidad? Los altos funcionarios, en ocasiones, ven con recelo la llegada al frente de sus Ministerios de ministros-técnicos surgidos en sus filas. $\mathrm{Y}$, además, experimentan protamente el inconveniente más grave de este sistema: mientras que el ministro-parlamentario coloca el peso de su autoridad política al servicio de su Administración, el ministro-alto funcionario no representa más que ésta...” (16).

Ciertamente, un ministro que llegue a su cargo con una formación y preparación adecuadas, podrá, en principio, desempeñar una tarea con mejor acierto y mayor competencia que un profano o que quien se haya especializado en materias distintas del Departamento que va a ocupar. Pero todo intento de establecer una regla general puede tener serias e importantes excepciones. Quizá dos de los más grandes ministros de Asuntos Exteriores que Inglaterra ha tenido en el siglo actual han sido Eden y Bevin: el

(15) - Bartheiemy y Duez, op. cit., p. 643.

(16) Goguel y Grosser: La politique en France, París, 1970, p. 270. 
DA-1980, núm. 188. JOAQUÍN TOMÁS VILLARROYA. Ministros y Gobierno en el Estado moderno. Un...

primero, con su formación, sus estudios y su experiencia conflictiva con Chamberlain, llegó al Foreing Office en el Gabinete de Churchill, sustituyendo a lord Halifax, con una preparación fuera de serie; el segundo, curtido en otros oficios ministeriales durante la guerra mundial, defendió luego los intereses de la Gran Bretaña y del mundo occidental, en circunstancias sumamente graves, con una destreza e inteligencia difícilmente superables. Dos juicios sobre ellos, propuestos por estadistas de otros paises, dibujan la fisonomía y competencia de cada uno. De Gaulle, refiriéndose a Eden, escribió: «Este ministro inglés, por muy inglés y muy ministro que fuese, mostraba una amplitud de miras y una sensibilidad más europea que insulares, más humanas que administrativas. Este hijo predilecto de las tradiciones británicas -Eton, Oxford, Partido Conservador, Cámara de los Comunes, Foreing Office- no por eso dejaba de ser sensible a cuanto tuviera visos de espontáneo e innovador. Este diplomático, enteramente consagrado a los intereses de su país, no menospreciaba los de los demás, y en medio de las cínicas brutalidades de su tiempo, se preocupaba aun de la moral internacional. Tuve que estar en relaciones a menudo con el señor Eden. Muchas de las cuestiones que hubimos de tratar eran francamente desagradables. Las más de las veces hube de admirar no sólo su brillante inteligencia, su conocimiento de los asuntos y el encanto de sus modales, sino también el arte con que sabía crear en torno a la negociación una atmósfera de simpatía que facilitaba el acuerdo cuando era posible llegar a él y que, en todo caso, evitaba las heridas... (17). Por su parte, Spaak veía a Bevin del siguiente modo: «Después de todos los ministros salidos de Eton, de Oxford y Cambridge, simbolizaba, por contraste, la llegada al poder de una nueva clase. Pero no había que engañarse por ello. La corteza rugosa disimulaba una aguda inteligencia, una firme voluntad, una perfecta honestidad intelectual, en el sentido de las responsabilidades, una gran fidelidad a la democracia, un sincero amor a la paz. De origen modesto y habiendo hecho su carrera en el movimiento sindical, era representativo de esos hombres, numerosos a fines del siglo pasado, que recorrieron, gracias a

(17) De Gaulle: Memorias de guerra. El llamamiento. 1940-1942. Trad. esp., p. 205. 
DA-1980, núm. 188. JOAQUÍN TOMÁS VILLARROYA. Ministros y Gobierno en el Estado moderno. Un...

sus propios esfuerzos, a sus propias cualidades, sin apoyos, sin disfrutar el menor privilegio, la larga carrera de los cargos y de los honores políticos. Durante la guerra se reveló capaz de ocupar con distinción los puestos más altos. Supongo que en el Foreing Office debió meditar muchas veces sobre su extraño destino, sobre el curso imprevisto de su carrera. Aun sin estar preparado clásicamente, acertó por completo probando una vez más que la técnica dista de ser indispensable en la función ministerial. Lo que importa es el juicio, el sentido de la responsabilidad, el espíritu de decisión, el afán de acción, el ardor en el combate. Dones todos que Bevin poseía en alto grado...» (18).

\section{La tarea del presidente del Gobierno}

La tarea de un ministro es agobiante, la de un primer ministro o presidente del Gobierno lo es de manera difícilmente expresable. La necesidad de fijar y coordinar una política, la creciente complejidad de los negocios públicos, la interpenetración de los asuntos internos $\mathrm{y}$ de los asuntos internacionales, han hecho prácticamente imposible la gestión separada de los diversos departamentos ministeriales. La mayoria de las decisiones de competencia de varios Ministerios se convierte en tema o cuestión de Gobierno reclamando la intervención de su presidente (19). La carga que pesa sobre éste es grande, variadísima, agotadora. Edgard Faure nos ha dejado un recuerdo gráfico y curioso de su primera experiencia como presidente del Gobierno, en la IV República, que duró, aproximadamente, cuarenta días: «Durante ese tiempo - comentaría luego- he estado sometido a una gimnasia agotadora que consiste en hacer dos cosas al mismo tiempo: preparar un discurso mientras recibía a un embajador, encontrar una solución financiera mientras participaba en una discusión política... El régimen de asamblea no es soportable para el presidente del Gobierno porque la partida entablada permanentemente entre él y seiscientos diputados no es igual. El diputado organiza su vida y puede conseguir que se le sustituya en la hora de votar. Puede comer, puede dormir. Este respiro está

(18) Spank: Combates sin acabar. Trad. esp., p. 177.

(19) Mortatt: Istituzioni di Diritto Pubblico, 5.a ed., 1960, p. 441. 
DA-1980, núm. 188. JOAQUÍN TOMÁS VILLARROYA. Ministros y Gobierno en el Estado moderno. Un...

prohibido al presidente del Consejo... Lo más extraordinario es que llegue a gobernar. Investido de las mayores responsabilidades, es árbitro en Consejo de Ministros. Es también el catalizador entre todas las tendencias de una mayoria inestable. Sólo que la política que hace, raramente es por completo la suya. Es un compromiso continuo entre el deseo de obtenerlo todo $\mathrm{y}$ el temor de romperlo todo.... (20).

Quizá una de las experiencias más interesantes y curiosas en el propósito de fijar y desarrollar ordenadamente una política fue la de Mendes-France en la etapa en que ocupó el mismo cargo en la IV República; Spaak, con una cierta perspectiva en el tiempo y en la lejanía, lo consideraba, después del general De Gaulle, como la personalidad política francesa más fuerte de la. posguerra, y valoraba aquel intento y experiencia en los términos siguientes: «Mendes-France se encontraba luchando con muchos problemas complicados, de los que el más importante era la guerra de Indochina. Habia establecido un calendario para sus actividades, concediéndose cuatro semanas para hacer la paz y luego, siguiendo un orden señalado por él, se había marcado ciertos plazos para resolver las demás cuestiones. Es una actitud intelectual seductora. Pero la política sería algo demasiado fácil de hacer si fuera posible poner en fila las dificultades y consagrarse a resolverlas sucesivamente una tras otra. En la realidad, las cosas son mucho menos sencillas. Los acontecimientos no esperan a producirse a gusto de los hombres. A veces se presentan juntos a su atención. Se mezclan y se enredan. En política hay que ser capaz de ocuparse de todo al mismo tiempo..." (21).

En efecto: el trabajo de un político y, desde luego, el de un presidente del Gobierno, difícilmente puede sujetarse a un orden - sistema. Cuando Willy Brandt llegó a la Cancillería, en un momento inicial, se hizo ilusiones que prontamente se desvanecieron: «Apenas si es posible-escribe-describir un día de trabajo típico del canciller federal. No existe. El día entero se pasa en una reunión sobre economía doméstica, el parlamento, la presidencia del partido, un viaje con motivo de una lucha electoral o un invitado extranjero. Otro dia se lo pasa uno estrechando

(20) La cita en Fauver: La IV République, 1959, p. 245.

(21) SpAAK, op. cit., p. 194. 
DA-1980, núm. 188. JOAQUÍN TOMÁS VILLARROYA. Ministros y Gobierno en el Estado moderno. Un...

0

las manos de los vistantes, si es que no está ocupado con conversaciones con pequeños grupos: cambio de impresiones de gabinete, representantes de los sindicatos, gremios del propio partido o de la fracción, conferencias de prensa y entrevistas... Todos los días se necesitaba hablar con mayor o menor intensidad con los colaboradores más estrechos, tomar nota de los resúmenes de prensa, estudiar los telegramas de los embajadores, incluir notas en las actas, escribir cartas importantes. Me ocupaba mucho tiempo leer los textos de los discursos, las tomas de posición, los artículos y las entrevistas escritas...” (22).

Un gran número de temas políticos y administrativos han de someterse, por su significado o su importancia, a la consideración del presidente del Gobierno; pero de manera muy especial los que se refieren a temas de política internacional y financiera. De ahí que aquél deba preocuparse directamente de éstos y que su contacto con los ministros encargados de tales asuntos haya de ser frecuente y dotado de mutua comprensión. En este punto son particularmente interesantes los testimonios que nos han dejado quienes desempeñaron el cargo de Premier en Inglaterra. Eden, ya tiempo atrás escribió: "Todo Ministro de Asuntos Exteriores, por individualista o absorbente que sea, sabe lo con: fortante que resulta discutir sus problemas con un colega de experiencia... En asuntos económicos y financieros, infinitamente más complicados y confusos en estos años que en los de antes de la guerra, un Ministro de Hacienda obrará prudentemente si, en cierta medida, comparte su carga con el Primer Ministro. Es evidente que no puede compartirla con todo el Gobierno...» (23). Mac Millan, recordando su experiencia de Premier, ha anotado: "La más estrecha e intima cooperación debe existir entre el primer ministro y el secretario del Exterior y el ministro de Hacienda. Casi todas las reuniones del Gabinete comienzan, primero, con una exposición de los problemas urgentes del exterior, seguida por un informe general de la economía... Ha pasado el tiempo en que un dictamen podía comentarse y redactarse de nuevo en una reunión del Gabinete en pleno... El dictamen, en estos días de telegramas y de teléfonos, ha perdido

(22) Willy BrandT: Memorias politicas 1960-1975. Trad. esp., 1976, t. I, p. 294.

(23) EDEN: Memorias 1945-1957. Trad, esp., 1960, p. 339. 
DÄ-1980, núm. 188. JOAQUÍN TOMÁS VILLARROYA. Ministros y Gobierno en el Estado moderno. Un...

su viejo significado. Pero apenas pasa un día en que el secretario del Exterior no encuentre unos momentos para visitar al primer ministro, probablemente con una propuesta de respuesta a algún mensaje del exterior, o al ministro de Hacienda para hablar acerca de alguna dificultad interna decisiva...» (24). Finalmente, Wilson, al recordar su llegada al poder, a mediados de octubre de 1964, señala que, de entrada, se encontró sobre la mesa con problemas internacionales de primera magnitud: «Los chinos -escribe- habian hecho explotar el día anterior su primer artefacto nuclear. Estaba ya redactada por el Foreing Office una inmediata declaración oficial que me recomendaban publicar. Les dije que la guardaran hasta que dispusiéramos de un secretario del Foreing Office y de una administración... Habia un telegrama que ponderaba la situación de la Unión Soviética tras el hundimiento del señor.Kruschev, menos de veinticuatro horas antes y el nombramiento del señor Kosyguin... Hubo una llamada telefónica del presidente Johnson... Había noticias inquietantes sobre la confrontación, la guerra entre Indonesia y Malasia, la zona de lucha donde el anterior Gobierno -con el apoyo laborista- había empeñado la mayor fuerza militar enviada a cualquier punto de combate desde el fin de la Segunda Guerra Mundial...» (25).

\section{El ministro de Asuntos Exteriores}

El cargo de ministro de Asuntos Exteriores es importante, prestigioso y delicado. Por esta razón, la coincidencia y acuerdo con el presidente del Gobierno son esenciales. En este sentido, dos antiguos primeros ministros ingleses, al relatar las discrepancias entre Neville Chamberlain y Eden, en 1938, se han remontado del episodio concreto a la formulación de una regla precisa: la necesidad de aquella coincidencia y conformidad. Churchill ha escrito: «El ministro de Asuntos Exteriores ocupa una posición especial en el Gobierno inglés. Se dedica mucho respeto y deferencia a su alto y responsable puesto, pero usual-

(24) Mac Mrluan: Pointing the Way, Londres, 1972, p. 33.

(25) Wilsow, op. cit., p. 23. 
DA-1980, núm. 188. JOAQUÍN TOMÁS VILLARROYA. Ministros y Gobierno en el Estado moderno. Un...

Estudios

mente ha de trabajar bajo la continua vigilancia de los principales miembros del Gabinete, cuando no todos. Tiene la obligación de informarles. Por costumbre y rutina envía a sus colegas todos sus telegramas ejecutivos, los documentos que envían a nuestras embajadas y los textos de sus pláticas con los embajadores $\mathrm{u}$ otras personalidades extranjeras... La inspección de las actividades de ese secretario corresponde, desde luego, al primer ministro, quien, personalmente, mediante su gabinete, tiene el deber y la facultad de dirigir la política extranjera. A él por lo menos no pueden guardársele secretos. No hay ministro de Asuntos Exteriores que pueda hacer nada si no le apoya su jefe. No sólo ha de concordar con él en lo fundamental, sino en sus miras e incluso en su temperamento..." (26). Por su parte, Mac Millan, al recordar el mismo episodio, ha señalado que el primer ministro $\mathrm{y}$ el ministro de Asuntos Exteriores deben discutir virtualmente todos los días los temas de política internacional: «El secretario del Foreing Office no sólo tiene que consultar a sus colegas antes de tomar decisión sobre alguna cuestión, sino que cada etapa de la negociación puede ser objeto de consideración y en algunos casos de sus criticas. Naturalmente, un primer ministro es responsable de toda la política de su Gobierno y debe estar en contacto, bien sea personalmente o a través de su despacho privado, con todos los Departamentos. Pero sus relaciones con el secretario del Foreing Office son de carácter especial. Lo ideal seria que hubiese una completa armonia de ideas sobre los asuntos públicos. Pero si, como ocurre en muchos casos, hay diferencias de enfoque y temperamento, ello les obliga aún más a que no haya secretos entre ellos..." (27).

Un modelo de lo que debe ser esta colaboración entre un presidente de Gobierno y un ministro de Asuntos Exteriores fue la que se estableció entre Churchill y Eden durante la Segunda Guerra Mundial y la que volvió a existir entre ellos después del Ministerio presidido por Atlee. En el último año de aquella guerra, Churchill, en la Cámara de los Comunes, trazó la semblanza y el elogio de quien había sido su colaborador y, con el tiempo, se convertiría en su sucesor: "Este es el momento adecuado

(26) Churchils: Memorias. Cómo se fraguó la tormenta. Trad. esp., 1865, p. 283.

(27) Mac Millan: Memorias. Cambiando el tiempo. Trad. esp., pp. 318-19. 
DA-1980, núm. 188. JOAQUÍN TOMÁS VILLARROYA. Ministros y Gobierno en el Estado moderno. Un...

—dijo el día 27 de febrero de 1945- para que la Cámara rinda tributo al trabajo de mi distinguido amigo nuestro ministro de Asuntos Exteriores. No acierto a describir a la Cámara la ayuda y utilidad que en todo momento he tenido en él. Su dura vida, cuando muy joven, sirvió en infantería en la última guerra; su constante autopreparación para las tareas que se le han encomendado; su inigualada experiencia como ministro de Asuntos Exteriores; su conocimiento de estos asuntos y de su pasada historia; su práctica de conferencias de todas clases; su amplitud de miras; sus facultades expositivas y su valor moral, le han valido una posición que no cede a ninguna entre los ministros de Asuntos Exteriores de la gran alianza. No sólo era deber mío, sino más aún de la Cámara, reconocer esto..." (28).

En la V República francesa las relaciones entre el general De Gaulle y Couve de Murville - salvando las diferencias de contextos políticos y los temperamentales - fueron también muy acordes. Ciertamente, De Gaulle no hubiera tolerado un ministro que resistiese sus indicaciones; pero seleccionó un ministro de Asuntos Exteriores que - según señala en sus Memorias- desplegó, en ese terreno, "una capacidad que muy pocos han igualado en el transcurso de una difícil historia...». En el largo elogio que De Gaulle dedica a Couve se condensa la alta estimación que le dispensó y el apoyo que le prestó: «Maurice Couve de Murville -escribe - tenía el don preciso. En medio de los problemas que se enredaban y de los argumentos que se enmarañaban, él supo distinguir al momento lo esencial de lo accesorio, de tal modo que era claro y preciso en materias que los cálculos hacen a cual más oscura y confusa. Tenia experiencia, ya que en el transcurso de su brillante carrera tuvo que tratar muchas cuestiones de actualidad y conoció a muchos hombres de Gobierno. Tenia seguridad, ya que estaba seguro de permanecer mucho tiempo en el puesto para el cual le llamé. Tenía aptitud: era hábil para entablar contacto, escuchando, observando $\mathrm{y}$ tomando nota, y luego sabía, en el momento preciso, formular con autoridad la postura de la cual ya no se apartaba. Tenía fe, ya que estaba persuadido de que Francia sólo perduraría poniéndose en

(28) El texto de Churchill en Obras escogidas. Trad. esp., 1957, p. 1161. 
DA-1980, núm. 188. JOAQUÍN TOMÁS VILLARROYA. Ministros y Gobierno en el Estado moderno. Un...

primera fila; de que con De Gaulle al frente era posible volver a situarla, y de que en el mundo nada tenía importancia más que esforzarse en lograrlo..." (29). Por su parte, Couve de Murville nos ha dejado también testimonio de su devoción a De Gaulle y de la coincidencia que entre los dos existió durante una década exacta: "Durante diez años - anota-, día a día, del 1 de junio de 1958 al 30 de mayo de 1968, he tenido el honor de ser el ministro de Asuntos Exteriores de Francia, cargo que no había tenido tan larga duración desde el Antiguo Régimen. El hecho, en sí mismo, quizá no tendría otro valor que su singularidad si no estuviese acompañado de una circunstancia que le confiere un carácter excepcional, a saber, a lo largo de ese período yo he estado asociado a la obra emprendida por Charles de Gaulle... Mi tarea no habría podido ser lo que fue si no hubiera existido, desde el primer momento, un acuerdo de algún modo espontáneo, instintivo, entre el presidente de la República y su ministro. De otra suerte, el uno no hubiera conservado al titular de Asuntos Exteriores a través de los cambios y reajustes que son normales en la vida política, incluso cuando la estabilidad gubernamental está asegurada y al otro no le hubiera sido posible, en conciencia, aportarle su colaboración...» (30).

\section{El ministro de Hacienda}

El ministro de Hacienda tiene, en principio, un poder e influencia que sólo puede quedar limitado $-\mathrm{y}$ no siempre- por la acción del presidente del Gobierno. En la República Federal Alemana, el artículo 26 del Reglamento Interior del Gobierno Federal, de 11 de mayo de 1951, dice así: «Si en una cuestión de importancia financiera el Gobierno Federal resuelve contra o sin el voto del ministro federal de Finanzas, puede éste formular expresamente oposición contra el acuerdo. Si se formula oposición conforme a lo señalado o en los casos legalmente previstos, se vota de nuevo el asunto en una posterior reunión del Gobierno Federal. La tramitación del asunto al que el ministro federal de

(29) De Gaulle: Memorias de la esperanza. La renovación. Trad. esp., 1970, páginas 201-202.

(30) Couve DE Munville: Une politique etrangère 1958-1989, París, 1871, p. 8. 
DA-1980, núm. 188. JOAQUÍN TOMÁS VILLARROYA. Ministros y Gobierno en el Estado moderno. Un...

Finanzas se ha opuesto debe sobreseerse si en la nueva votación en presencia del ministro federal de Finanzas o de su sustituto no es resuelto por la mayoría de todos los ministros federales y el canciller vota con la mayoría." En Francia ese veto no aparece formalmente reconocido; pero, de hecho, existe; en este sentido, es interesante señalar que Pompidou, siendo primer ministro, le confiaba a Alain Peyreffitte: «Cuando Hacienda está contra una reforma, tiene pocas probabilidades de prosperar. Cuando a la vez Hacienda y el Ministerio técnico a quien concierne están contra una reforma, no tiene absolutamente ninguna posibilidad..." (31). En efecto: la experiencia demuestra que en Francia -y en los demás países- la descentralización, la regionalización, la distribución de competencias, las autonomías locales, los derechos mismos de los ciudadanos son palabras vanas si eI Ministerio de Hacienda opone su veto o su inercia. El poder deI ministro de Finanzas se explica si se tiene en cuenta que, con diversas variantes de uno a otro país, recauda el dinero, organiza su distribución y lo distribuye; informa y frecuentemente redacta los reglamentos que permiten la aplicación de las leyes más importantes; controla todos los gastos del Estado y de los sectores que dependen del Estado; dispone de funcionarios o interventores en todos los Ministerios; organiza en su propio seno contra ministerios técnicos que vigilan los proyectos de los demás Ministerios.

Un ministro que quiera cumplir eficazmente su tarea y lograr sus propósitos debe cuidar especialmente sus relaciones con el Ministerio de Hacienda. En este sentido, Robert Buron, refiriéndose a la IV República, señalaba, con deliciosa mezcla de realismo y de ironía, que aquél procurará, en tales relaciones observar las reglas siguientes: «Debe, ante todo, tratar de mantener relaciones personales amistosas con su colega y será conveniente que las esposas lleguen a ser amigas. Un encuentro familiar y distendido permite decir muchas cosas y preparar o anudar acuerdos... Debe tener en su Gabinete a un inspector de Finanzas en quien pueda depositar toda su confianza. La edad ideal de este colaborador debe situarse alrededor de los treinta

(31) Peyneffitte, op. cit., p. 268. 
DA-1980, núm. 188. JOAQUÍN TOMÁS VILLARROYA. Ministros y Gobierno en el Estado moderno. Un...

y cinco años, ya que de este modo será seguramente compañero de promoción de los subdirectores de la calle Rívoli y de los miembros del gabinete del gran tesorero... El ministro inculcará a todos los altos funcionarios de su Departamento la idea de que, en las relaciones oficiales, los funcionarios de Hacienda tienen derecho a la consideración que corresponde a quienes en otras Administraciones ostentan un grado superior. Los directores no deben considerarse disminuidos por el hecho de pedir audiencia a los subdirectores del Presupuesto o del Tesoro... El ministro no debe dudar en dispensar al director del Presupuesto o al jefe del Gabinete del ministro de Finanzas un tratamiento amistoso, e incluso tratarles como colegas. Ciertamente, no debe pedirles audiencia; pero les telefoneará frecuentemente y procurará mostrar conocimiento profundo de los temas de que les hable. Cuando deba tener una conversación con su colega, le sugerirá la presencia de sus colaboradores de mayor confianza, o, al menos, antes de marcharse, procurará ir a estrecharles su mano...» (32).

Por su parte, Peyreffitte, en relación a la V República, ha trazado, brevemente, un cuadro que en esencia coincide con el anterior: «La omnipotencia administrativa es a dos escalas. Hay la de la Administración sobre todo lo que no es ella misma: Y después está la que Hacienda ejerce sobre todo el resto de la Administración. Tantos despachos que hacen temblar, tiemblan ellos mismos ante los despachos de la calle Rivoli, pero ellos no tiemblan ante nadie... Es creencia general que el primer ministro fija las grandes líneas del presupuesto gubernamental. $\mathrm{Y}$ que después cada ministro es responsable de repartir los medios económicos que le son atribuidos. En modo alguno: debe justificar céntimo a céntimo en cada medida, dentro de cada capítulo presupuestario. No ante el primer ministro ni ante el ministro de Hacienda, sino ante el agente especializado de la dirección del Presupuesto, el cual discute hasta en los detalles más ínfimos lo bien fundado de cada una de las iniciativas que desea tomar el ministro. La respuesta es, con frecuencia, negativa. ¿Debe entonces «ascender al arbitraje» del primer ministro? Procedimiento arriesgado: el árbitro no puede apenas una vez

(32) R. Bunon: Le plus beau des metiers, París, 1963, pp. 214 y ss. 
DA-1980, núm. 188. JOAQUÍN TOMÁS VILLARROYA. Ministros y Gobierno en el Estado moderno. Un...

sobre dos tomar partido por el gastador contra el ahorrativo, y con frecuencia Hacienda demostrará una mala gana hábil para aplicar una decisión tomada contra su opinión. Es más sensato arreglarse con la calle Rívoli, es decir, reconocer su soberanía y mendigar su benevolencia...” (33). Quizá por esta razón el reciente desdoblamiento en Francia del Ministerio de Economía y de Finanzas ha tratado de limitar la omnipotencia que la rue Rivoli ejercía sobre la vida económica del país. Es todavía prematuro advertir las consecuencias de esta división, ni puede predecirse si tendrá o no carácter definitivo: en todo caso, la ruptura de la ciudadela ha sido considerada gráficamente como un golpe de Estado o una revolución.

En otro orden de cosas, es interesante señalar que la política económica y financiera de un país tiene, en la actualidad, tales implicaciones internacionales que el poder del ministro de $\mathrm{Ha}$ cienda queda disminuido y la misma soberanía del Estado limitada. En este punto, el testimonio de Wilson es sumamente revelador. "Este libro - dice en la introducción a El Gobierna laborista - traza la historia de un Gobierno, cuya vida, exceptuando un solo año, estuvo dominada por un problema heredado de la balanza de pagos que, al asumir nosotros el cargo, se estaba aproximando a la crisis; estuvimos viviendo y gobernando durante un periodo en que este problema convirtió los ataques de frenética especulación contra Inglaterra en algo fácil y provechoso...» (34). Después de la formación de Gobierno y una vez aprobado el discurso de la Reina, el interés parlamentario se centró en la declaración que Callaghan iba a pronunciar en eI Comité de Recursos y Medios el 11 de noviembre: «Se trataba en realidad -escribe- de un presupuesto de otoño. Aprovechó la oportunidad para anunciar aumentos de los beneficios sociales... Anunció dos grandes reformas impositivas... Pronto íbamos a comprender que las decisiones referentes a las pensiones y a los impuestos no podían considerarse ya, como antes, de la sola incumbencia del Parlamento. La combinación de impuestos más elevados con prestaciones más altas de la Seguridad Social provocaron el primero de una serie de ataques a la libra esterlina

(33) Peyreffitte, op. cit., pp. 333-334.

(34) Wilson, op. cit., p. 17. 
DA-1980, núm. 188. JOAQUÍN TOMÁS VILLARROYA. Ministros y Gobierno en el Estado moderno. Un...

por parte de especuladores y de otros, que pusieron cerco a casi todas las acciones del Gobierno durante los cinco años siguientes...". En un determinado momento, Wilson tuvo que decirle al Gobernador del Banco de Inglaterra «que habíamos llegado a un punto en que a un Gobierno recién elegido por un mandato del pueblo le decían, no el gobernador del Banco de Inglaterra, sino los especuladores internacionales, que la política sobre la cual había luchado en las elecciones no podía llevarse a cabo; que habia que obligar al Gobierno a adoptar la política tory a la cual se oponía de modo fundamental. El gobernador confirmó que de hecho así era...) (35). La reacción de Wilson encerraba una decisión política y constitucional: «Le dije que si esto era así, no estaba dispuesto a aceptarlo. Lo que me estaba diciendo no era solamente que estaba en peligro el programa social y además todo nuestro mandato en favor de la reforma, sino la misma democracia. Aceptar este argumento significaba pedir al primer ministro de la Reina que bajara el telón sobre la democracia parlamentaria y aceptar la doctrina de que una elección en Gran Bretaña era una farsa, que el pueblo británico no podía escoger entre varias opiniones políticas, y que la política era dictada desde el exterior del país, principalmente, por gente que no comprendía a Gran Bretaña y que basaba su información sobre el consejo de personas cuyos motivos iban desde la ignorancia a la malicia..." (36).

\section{Los Consejos de Ministros}

Por regla general, las reuniones del Gobierno se celebran, en la mayoria de los países, según usos más a menos consistentes y según criterios que suelen cambiar a medida en que lo exigen la experiencia o las necesidades. Pero es de todo punto imprescindible señalar, en este lugar, que en la República Federal Alemana el Reglamento Interior del Gobierno Federal determina minuciosamente la preparación, reunión, asistencia y adopción de acuerdos por el Gobierno.

(35) lbid., p. 58 .

(36) Ibid., p. 63 . 
DA-1980, núm. 188. JOAQUÍN TOMÁS VILLARROYA. Ministros y Gobierno en el Estado moderno. Un...

a) En relación a la preparación, el artículo 21 dispone: «1. Las reuniones del Gobierno Federal se señalan por el secretario de Estado de la Cancillería Federal, según instrucciones detalladas del Canciller Federal. El cuida de enviar la convocatoria para las sesiones con inclusión de un orden del día. 2. Los proyectos y exposiciones preparados por los ministros federales se remiten al secretario de Estado de la Cancillería Federal en número suficiente de ejemplares; al mismo tiempo; deben ser enviados directamente a todos los ministros federales y al jefe de la Oficina Presidencial Federal. 3. El envio de las propuestas de que hayan de someterse al Gabinete deben tener lugar con la anticipación necesaria para que permita un examen efectivo de las mismas antes de la deliberación. Entre la entrega de la propuesta al secretario de Estado de la Cancillería Federal y a los ministros federales y su deliberación debe mediar, por lo menos, una semana, si se trata de un proyecto de ley importante o de otras propuestas de singular interés y si el plazo no ha sido observado, el asunto, a petición de dos ministros federales o de sus sustitutos debe ser retirado del orden del día a no ser que el canciller federal considere necesaria la inmediata deliberación."

b) En relación a las reuniones, el artículo 22 prescribe: 1. "Las sesiones del Gobierno Federal tienen lugar bajo la presidencia del canciller federal y, en caso de impedimento, bajo la presidencia del vicecanciller federal. Si éste estuviere también impedido, la presidencia corresponde al ministro federal especialmente designado por el canciller federal o el vicecanciller, o, a falta de tal designación, al ministro federal que más tiempo ha permanecido ininterrumpidamente en el Gobierno Federal, y de haber varios ministros federales del mismo mandato asume la presidencia el ministro federal de más edad. 2. Las sesiones comienzan puntualmente a la hora indicada en la convocatoria. Los ministros federales impedidos deberán cuidar de su sustitución. 3. Las reuniones del Gobierno Federal son secretas. De manera particular, quedan prohibidas, salvo autorización expresa del canciller federal, las comunicaciones relativas a las declaraciones de los distintos ministros federales, a las votaciones y al contenido de las actas." 
DA-1980, núm. 188. JOAQUÍN TOMÁS VILLARROYA. Ministros y Gobierno en el Estado moderno. Un...

c) En relación a las asistencias o presencias en las sesiones, el artículo 23 dispone: «1. En las reuniones del Gobiemo Federal toman parte regularmente, además de los ministros federales, del secretario de Estado en la Cancillería Federal y del secretario de Estado Parlamentario del Canciller, el jefe de la Oficina Presidencial Federal, el jefe federal de Prensa, el Consejero Personal del Canciller Federal y el secretario. 2. Si un ministro no puede participar en una reunión del Gobierno Federal, el secretario de Estado Parlamentario le sustituye en la reunión. El ministro Federal puede disponer que en casos particulares intervenga en la reunión, junto a él, el secretario de Estado. 3. Si un ministro federal considera oportuna la asistencia de un funcionario de su Ministerio, aparte del secretario de Estado, debe anunciarlo por escrito con expresión del nombre del funcionario. El presidente decide sobre la admisión a la reunión. El funcionario participa en la reunión solamente el tiempo que dure la discusión sobre el punto para el que se le llama. 4. El canciller federal puede limitar la reunión a los ministros federales.»

d) En relación a los acuerdos, deben considerarse tres artículos. El artículo 24 dice: «1. El Gobierno Federal sólo puede adoptar decisiones cuando esté presente la mitad de los ministros federales, incluido el presidente. 2. El Gobierno Federal adopta sus decisiones por mayoria de votos. En caso de igualdad decide el voto del presidente.» El artículo 25 añade: «El texto de las decisiones adoptadas por el Gobierno Federal será fijado por el presidente después de la deliberación de cada asunto.» $Y$ el artículo 27 concluye: «De las reuniones del Gabinete Federal se levanta un acta firmada por el secretario. Una copia del acta se envía en breve plazo a los ministros federales. El jefe de la Oficina Presidencial Federal y el jefe federal de Prensa reciben una copia del acta para su conocimiento. 2. El acta se considera aprobada si en los tres días siguientes a su envío a los ministros federales interesados no oponen reparos a su contenido o a la redacción. 3. En casos de duda el asunto debe someterse de nuevo al Gobierno Federal.».

En cambio, en Francia no existe regulación que fije con precisión el régimen y condiciones de las reuniones ministeriales; pero existen testimonios varios que describen el ambiente que 
DA-1980, núm. 188. JOAQUÍN TOMÁS VILLARROYA. Ministros y Gobierno en el Estado moderno. Un...

rodea a las mismas. León Blum, todavia bajo la Tercera República, lamentaba que las reuniones del Gobierno resultaban escasamente útiles. Laniel nos ha dejado una descripción detallada de una reunión ministerial en la Cuarta República: en el curso de la misma se alternaban reuniones anodinas con otras de singular dramatismo. De los Consejos en la Quinta tenemos dos descripciones: la una, mayestática, del general De Gaulle; la otra, desmitificadora, debida a Françoise Giroud. El General, en sus Memorias, ha escrito: "Una vez por semana, no más por lo general, y siempre bajo mi presidencia, se reunía el Consejo de Ministros. Asistian todos, así como los secretarios de Estado, porque sólo habia una política de gobierno, y para quienes la asumian, la solidaridad no se dividía... Las sesiones se desarrollaban con arreglo al orden del día fijado y notificado de antemano por mí, ateniéndome, por lo general, a lo que me había solicitado el primer ministro y me habían expuesto conjuntamente el secretario general de la Presidencia, Geoffroy de Courcel, y el secretario general del Gobierno, Roger Balin. Estos dos altos funcionarios, en el centro y al corriente de todo, eran mudos espectadores de la reunión y tomaban acta de las decisiones... Por medio de comunicaciones de los ministros se iban sometiendo por turno al Consejo todas las cuestiones referentes a los poderes públicos, bien porque dieran lugar a exposiciones y discusiones de conjunto, bien porque implicasen en la adopción de un texto: proyecto de ley, comunicado; bien porque requiriesen una solución inmediata... Todos podían pedir la palabra: siempre se les concedió. En los casos más importantes, yo invitaba a todos los miembros a que manifestasen su parecer. De todas maneras, el primer ministro presentaba sus argumentos y sus propuestas. Para resumir, yo indicaba cuál era mi manera de ver y formulaba la conclusión. Después de lo cual, la relación de las decisiones quedaba fijada por mí personalmente y a mí acudía el ministro de Información a recabar las directrices acerca de lo que iba a dar a conocer al público de la reunión que terminaba..." (37).

Sin embargo, quizá sea interesante señalar, en relación a los últimos extremos, que historiadores y comentaristas de la Pre-

(37) De Gaulle, op. cit., t. I, pp. 315-8. 
DA-1980, núm. 188. JOAQUÍN TOMÁS VILLARROYA. Ministros y Gobierno en el Estado moderno. Un...

sidencia gaullista subrayan que el general adoptaba frecuentemente sus decisiones $\sin$ consultar a sus ministros. VianssonPonté refiere que en la sesión del Consejo de Ministros del 26 de agosto de 1959 el general invitó a los ministros a pronunciarse sobre el tema de Argelia; Pinay replicó en los términos siguientes: "Yo no sé nada más que lo que leo en los periódicos. Yo no sé nada más que lo que sabe el hombre de la calle. Si se me pregunta en esta condición, puedo decir lo que pienso. Pero a falta de documentación sobre el plan político y militar, ¿cómo queréis que expongamos válidamente nuestro punto de vista?..." (38). Por su parte, Mitterand, desde su permanente oposición, generaliza y en durece la crítica: "Francia - escribió- tiene ministros. Se murmura que cuenta incluso con un primer ministro. Pero lo que ya no tiene es un Gobierno. El presidente de la República es el único que ordena y decide. Bien es cierto que los ministros son llamados ritualmente a proporcionarle ayuda y consejo. Pero al igual que los querubines del Antiguo Testamento, ocupan tan sólo un rango modesto en la jerarquía de los servicios elegidos y no desempeñan su augusta función, sino cuando son llamados para ello...” (39).

Una imagen diversa, desenfadada e irónica de los Consejos de Ministros en la Quinta República, bajo la presidencia de Giscard d'Estaign, nos la ofrece Françoise Giroud en su brillante libro La comédie du pouvoir. En el Consejo pueden distinguirse varios momentos o etapas:

a) Por de pronto, la antigua ministra de Giscard y de Chirac describe el ambiente previo a la celebración del Consejo: «La sala en que se celebra, todos los miércoles, por la mañana, el Consejo de Ministros es uno de los lugares privilegiados en que se representa la comedia del poder... Los ministros entran por una puerta. La del centro está cerrada. El presidente de la República y el primer ministro llegan por la tercera... Entre las q h. 20' y 9 h. 30' todo el mundo llega, cartera en mano, conteniendo el orden del día de la reunión que ha sido fijado el lunes por la tarde por el presidente y los proyectos de ley que serán

(38) Viansson-Pontí: Histoire de la République Gaullienne, t. I, p. 204.

(39) Mitrenand: El golpe de Estado permanece. Trad. esp., 1868, p. 106. 
DA-1980, núm. 188. JOAQUÍN TOMÁS VILLARROYA. Ministros y Gobierno en el Estado moderno. Un...

examinados... Durante algunos minutos se saluda, se bromea, se cambian impresiones o informaciones. El tuteo es corriente; el empleo del nombre, obligado... El presidente aparece seguido del primer ministro, con el que se entrevista siempre antes del Consejo... Da la vuelta a la mesa, estrecha la mano, dice una palabra a uno y a otro, y abre la sesión, indicando, en su caso, quién está ausente por razones de viaje y los secretarios de Estado que están presentes...»

b) Después la sesión comienza: el presidente de la República concede la palabra a "quien expondrá las razones por las que propone una disolución de un Consejo municipal, el nombramiento o separación de un alto funcionario, la conformidad a tal embajador, a tal oficial superior... Los grados elevados en la Orden de la Legión de Honor se someten igualmente a la aprobación del Consejo o, al menos, a un simulacro. En efecto, cada una de las medidas así propuestas no llega ante el Consejo sin haber sido sometida y aprobada por el Elíseo, Matignon y, en su caso, por el ministro a cuyo Departamento afecta... En lo que yo recuerde, ninguna propuesta en el Consejo ha sido nunca rechazada... No obstante, después de cada intervención, el presidente pregunta: ¿Alguna observación?...».

c) En el curso del Consejo se examinan los proyectos de Ley: "No existe ley - sigue comentando la Giroud- que sea secundaria, si bien algunas tienen más amplitud que otras en su contenido y en sus consecuencias. Pero su exposición, preparada por los servicios, redactada en estilo administrativo y siempre según las reglas de la disertación más bien que del discurso, destila un aburrimiento cuyo grado varia según la voz y las entonaciones del que habla. O mejor, de quien lee... Cuando el tecnicismo se mezcla resulta más difícil encontrar en esa prosa intrincada los asideros a los cuales el ịterés puede agarrarse... De otra parte, los textos han sido distribuidos en los días que preceden, de manera que cada uno puede haber tenido un conocimiento previo. Entonces, ¿para qué esa lectura en voz alta? Porque sumergido en sus propios dossiers, nadie ha tenido tiempo de consultar los papeles que el secretario general del Gobierno distribuyó con la mención de secreto... El presidente y el primer ministro rebuscan en sus papeles y cambian con sus vecinos in- 
DA-1980, núm. 188. JOAQUÍN TOMÁS VILLARROYA. Ministros y Gobierno en el Estado moderno. Un...

mediatos, en voz baja, comentarios sin relación con el asunto que debe ocupar su atención. La somnolencia o el nerviosismo, según la naturaleza de unos u otros, se apodera de la asistencia..."

d) En la última fase el Consejo puede ser más interesante e instructivo: según un calendario previamente establecido, cada ministro periódicamente expone aante el Consejo la actividad de su departamento y la politica que pretende seguir en su sector... El contenido de tales comunicaciones debe remitirse previamente al Elíseo y a Matignon con algunos días de anticipación... En esta misma línea el ministro de Asuntos Exteriores informa casi todas las semanas sobre la situación internacional y quienes regresan de un viaje al extranjero dan cuenta del mismo... La práctica es interesante, ya que es la única ocasión en que los miembros del Gobierno se informan de lo que sucede y de lo que se prepara más allá de su propio campo de acción...”. En fin, después de informes e intervenciones de muy diferente sentido, `el Consejo de Ministros acaba siempre "con una exposición del presidente relativa a la actualidad, situando los acontecimientos en su perspectiva y describiendo las líneas de actuación... Se sale por pequeños grupos... Los periodistas pasan al asalto, con todos los micrófonos prestos, inevitablemente persuadidos de que el Consejo ha sido el teatro de graves revelaciones, de discusiones apasionadas, de decisiones capitales..." (40).

\section{La estabilidad del Gobierno}

Un Gobierno, en todo tiempo, pero sobre todo en la actualidad, necesita, para cumplir su tarea con eficacia, de estabilidad y duración: sólo con una política dotada de continuidad se puede servir debidamente al Estado. Y, sin embargo, aun en nuestros dias, los supuestos de inestabilidad han sido constantes -por citar los ejemplos más importantes- en la Cuarta República Francesa y en la' Italiana postfascista. En relación a la Cuarta República, disponen de testimonios varios $\mathrm{y}$ autorizados:

(40) Grnoud: La Comédie du Pouvoir, Paris, 1977, p. 24. Las citas han sido extraidas del capitulo II, dedicado integramente a la reunión del Consejo de Ministros. 
DA-1980, núm. 188. JOAQUÍN TOMÁS VILLARROYA. Ministros y Gobierno en el Estado moderno. Un...

Por de pronto, Pflimlin, en los días de agonia del régimen, decía: "La vacante de poder una vez más paraliza al Estado. Tres veces en menos de un año, el esfuerzo de la nación ha sido contrarrestado por tres crisis ministeriales. En doce meses la República ha permanecido tres meses sin dirección, sin política, en unos tiempos en que el ritmo de la Historia se acelera, en un mundo que ha cesado de esperar nuestras decisiones para decidirse... El espectáculo de esta inestabilidad es indigno de un pueblo cuyas energías están intactas y que permanece siendo capaz de consentir unos sacrificios para la grandeza del país. Debilita, hasta un grado de desafección que se ha vuelto temible, la adhesión de los franceses para el régimen. La degradación de nuestras instituciones amenaza a la República en su existencia... Un gobierno puede ser derrocado por una adición momentánea de minorias opuestas una a otra, incapaces de unirse para constituir una mayoría positiva... Resulta claro que nuestras libertades solamente serán salvaguardadas si la autoridad, la fuerza y el prestigio vuelven a ser, con la duración, los atributos del poder...» (41).

Por su parte, Mendes-France, ya caída la Cuarta República, recordaba que en la misma el Gobierno estaba virtual y constantemente paralizado en su decisión y política: «Perpetuamente amenazado de revocación, privado de toda perspectiva de subsistir, el ejecutivo se encontraba en la incapacidad de manifestar su voluntad independiente. Se esforzaba aun cediendo a presiones y hostigamientos por conciliar intereses incompatibles. El inmovilismo era el precio de estas argucias. No existía, de hecho, un Gobierno digno de este nombre. Una veintena de hombres llevaban el título de ministros y se sentaban en los palacios nacionales, pero no constituían un poder. En su trabajo diario no gozaban de ningún margen de libertad o de tiempo, no podían nada decidir, nada emprender, nada terminar por su propia cuenta..." (42). Y el propio Mendes-France aporta el testimonio de Hirsch, comisario del Plan, quien se expresaba en los siguientes términos: "Yo he tenido personalmente relación, en trece años, con veintiséis Gobiernos. Lo que equivale a decir que los

(41) La cita en Peyrefitte, op. cit., pp. 68-9.

(42) Mendes-France: La República moderna. Trad. esp., p. 29. 
DA-1980, núm. 188. JOAQUÍN TOMÁS VILLARROYA. Ministros y Gobierno en el Estado moderno. Un...

Estudios

Gobiernos no eran los mismos al elaborarse el plan, luego al disputarse en el Parlamento y, por último, en período de ejecución. Una gran parte de tiempo se pasaba en explicar a los ministros que habian de responder a una interpelación o estaban bajo las amenazas de una crisis, lo que convenia preparar para los cuatro años siguientes, y varias veces he tenido la impresión de que el ministro, al cual me dirigia, se preguntaba si yo me daba perfecta cuenta de la situación en que se encontraba..." (43).

Por último, De Gaulle, en sus Memorias pasa lista a los nombres de los que ocuparon, bajo la IV, el cargo de presidentes del Gobierno: «Todos ellos -escribe-hombres de gran valía y sin lugar a dudas capacitados para los negocios públicos...; pero que se vieron sucesivamente privados, por lo absurdo del régimen, de ejercer una influencia real sobre los acontecimientos. ¡Cuántas veces, viéndoles debatirse lejos de mí, en lo imposible, me entristeció este despilfarro de cualidades humanas! Por muy importante que fuese lo que cualquiera de ellos intentara, el país y el extranjero asistían al escandaloso espectáculo de "Gobiernos" formados a fuerza de compromisos, sañudamente criticados en cuanto se reunían, desquiciados en su propio seno por las discordancias y disidencias, rápidamente derribados por una votación que en la mayoría de los casos sólo reflejaba el impaciente apetito de los candidatos a las carteras, y que en sus intervalos dejaban unas lagunas que, a veces, duraban más de una semana. Ádemás, en el tablado donde se representaba la comedia, se presenciaba en los entreactos las salidas o mutis de los presidentes "consultados", o "propuestos", o "ratificados", hasta que uno de ellos aceptaba el cargo. En el Elíseo, Vicent Auriol y luego René Coty, jefes de Estado que no podían remediarlo, aunque muy otra fuese su preocupación por el bien público y la dignidad ministerial, presidían con resignación las irrisorias figuras de ese ballet...» (44).

(43) Ibid., p. 30 .

(44) De Gaulle, op. cit., pp. 16-17. 
DA-1980, núm. 188. JOAQUÍN TOMÁS VILLARROYA. Ministros y Gobierno en el Estado moderno. Un...

\section{Conclusión}

El presente estudio esboza solamente unas consideraciones y reflexiones sobre la composición del Ministerio, las reuniones del Consejo de Ministros, las tareas que pesan sobre el presidente del Gobierno y los ministros, la igualdad formal y la preeminencia real de determinados Ministerios sobre otros. Sin duda, de este estudio, difícilmente podrán extraerse conclusiones útiles ni operantes. Pero en él se apunta o pretende apuntar una línea que, posiblemente, otros estudios deberian ratificar o rectificar $\mathrm{y}$, en todo caso, ampliar, llegando a conclusiones que permitan un mejor conocimento del Gobierno, de su funcionamiento, de sus insuficiencias. Es necesario tener presente que un Ministerio está formado por hombres que tienen sus limitaciones y sobre los cuales pesan tareas y responsabilidades que, frecuentemente, no pueden soportar ni realizar de manera eficaz. Es necesario tener presente que la máquina actual de todo Gobierno se resiente de falta de coordinación y que la Administración sufre una lentitud y una pesadez que daña al interés público y al de los particulares. El libro de Alain Peyrefitte, citado en estas páginas, es un espléndido estudio que, con sólo cambiar nombres y detalles secundarios, puede reflejar y refleja los defectos que afectan al Gobierno y a la Administración en muchos países. Las denuncias y el mal están ya dibujados. Ahora, es menester que una reflexión detenida y la experiencia madurada permitan llevar, en su día, a los textos legales las normas que rectifiquen errores, dispersión y premiosidades; que permitan el perfeccionamiento de la organización y funcionamiento del Gobierno ajustándolo a las necesidades de la sociedad en los tiempos actuales. En suma: es necesario que de la observación y la experiencia surja una doctrina política y una normativa que responda a las exigencias actuales y a los tiempos que se avecinan. 
DA-1980, núm. 188. JOAQUÍN TOMÁS VILLARROYA. Ministros y Gobierno en el Estado moderno. Un...

DA-1980, núm. 188. JOAQUÍN TOMÁS VILLARROYA. Ministros y Gobierno en el Estado moderno. Un... 